\title{
Pengembangan Bahan Ajar Kimia Berbasis Integrasi Islam-Sains Materi Minyak Bumi Sebagai Implementasi Pendidikan Karakter
}

\author{
Ana Faeha ${ }^{*}$, Abdul Wahid ${ }^{2}$ dan Wirda Udaibah ${ }^{3}$ \\ 1Madrasah Aliyah Azzaky Kota Pekalongan, Indonesia \\ 2,3Program Studi Pendidikan Kimia Fakultas Sains dan Teknologi Universitas Islam Negeri Walisongo \\ Semarang, Indonesia \\ *Email: ana.faena@gmail.com
}

\begin{abstract}
The low learning outcomes of students in hydrolysis material especially at the microscopic level and the learning process which still uses conventional learning methods at MA Uswatun Hasanah, so this research was conducted. The POGIL (Process Oriented Guided Inquiry) model with Multiple Level Representation is expected to be able to determine the level of mastery of concepts and retention of MA Uswatun Hasanah students on hydrolysis material. Method: This study uses one sample to obtain research data, namely class XI majoring in science. The research data was obtained by the documentation method to obtain a list of names of XI grade students at MA Uswatun Hasanah's science department and test methods to obtain data on student learning outcomes obtained from the values of pretest, posttest, and retest. Results: This study shows that learning through the POGIL model with Multiple Level Representation can increase the level of mastery of concepts and retention of students of class XI IPA MA Uswatun Hasanah. There are 30\% of students experiencing an increase in mastery of the concept of high categories, $40 \%$ of students experience an increase in mastery of the concept of the medium category, and $30 \%$ experience an increase in mastery of the concept of the low category. The retention rate of participants of the XI IPA MA Uswatun Hasanah class is 92.7\% which is high. Based on the results of the research that has been done, it can be concluded that Learning using the POGIL model with Multiple Level Representation can increase the level of mastery of concepts and retention of students of class XI IPA MA Uswatun Hasanah.
\end{abstract}

Kata kunci : Mastery of Concepts, Retention, POGIL Models, Multiple Level Representation, Hydrolysis 


\begin{abstract}
Abstrak
Rendahnya hasil belajar peserta didik pada materi hidrolisis khususnya pada level mikroskopik dan proses pembelajaran yang masih menggunakan metode pembelajaran konvensional di MA Uswatun Hasanah, sehingga dilakukan penelitian ini. Model POGIL (Process Oriented Guided Inquiry Learning) bermuatan Multiple Level Representation diharapkan dapat mengetahui tingkat penguasaan konsep dan retensi peserta didik MA Uswatun Hasanah pada materi hidrolisis. Metode: Penelitian ini menggunakan satu sampel untuk memperoleh data penelitian yaitu kelas XI jurusan IPA. Data penelitian diperoleh dengan metode dokumentasi untuk mendapatkan daftar nama-nama peserta didik kelas XI jurusan IPA MA Uswatun Hasanah dan metode tes untuk memperoleh data hasil belajar peserta didik yang diperoleh dari nilai pretest, posttest, dan retest. Hasil penelitian : Penelitian ini menunjukkan bahwa pembelajaran melalui model POGIL bermuatan Multiple Level Representation dapat meningkatkan tingkat penguasaan konsep dan retensi peserta didik kelas XI IPA MA Uswatun Hasanah. Terdapat 30\% peserta didik mengalami peningkatan penguasaan konsep kategori tinggi, 40\% peserta didik mengalami peningkatan penguasaan konsep kategori sedang, dan 30\% mengalami peningkatan penguasaan konsep kategori rendah. Adapun tingkat retensi peserta kelas XI IPA MA Uswatun Hasanah adalah 92,7\% yang tergolong tinggi. Berdasarkan hasil penelitian yang telah dilakukan, dapat disimpulkan bahwa Pembelajaran dengan menggunakan model POGIL bermuatan Multiple Level Representation dapat meningkatkan tingkat penguasaan konsep dan retensi peserta didik kelas XI IPA MA Uswatun Hasanah.
\end{abstract}

Kata kunci : Penguasaan Konsep, Retensi, Model POGIL, Multiple Level Representation, Hidrolisis

\section{Pendahuluan}

Perkembangan Sains dan Teknologi semakin terasa pesat dan diperlukan manusia Manusia modern sudah sangat bergantung kepada produkproduk sains dan teknologi. Sukar untuk dibayangkan manusia modern hidup tanpa menggunakan produk-produk sains dan teknologi. Keperluan hidup harian manusia modern mulai dari makan, minum, tidur, tempat tinggal, tempat bekerja, alat-alat transportasi, sampai alat-alat komunikasi, alat-alat hiburan, kesehatan dan semua aspek kehidupan manusia tidak terlepas dari pada menggunakan produk sains dan teknologi. Kata sains dan teknologi ibarat dua sisi mata uang yang sulit dipisahkan satu sama lain. Sains, menurut Baiquni, adalah himpunan pengetahuan manusia tentang alam yang diperoleh sebagai konsensus para pakar, melalui penyimpulan secara rasional mengenai hasil-hasil analisis yang kritis terhadap data pengukuran yang diperoleh dari observasi pada gejala-gejala alam. Sedangkan teknologi adalah himpunan pengetahuan manusia tentang proses-proses pemanfaatan alam yang diperoleh dari penerapan sains, dalam kerangka kegiatan yang produktif ekonomis (Baiquni, 1995).

Sains dan teknologi melekat erat ke dalam kehidupan modern, diantaranya adalah ilmu kimia. Ilmu kimia adalah ilmu yang mempelajari tentang peristiwa atau fenomena yang terjadi di alam, lebih spesifiknya lagi mempelajari tentang materi dan perubahan yang menyertainya(Chang, 2004). Kimia merupakan salah satu mata pelajaran sains yang dipelajari di Madrasah Aliyah (MA) sederajat dengan SMA yang pada dasarnya sama dalam hal pembelajaran ilmu-ilmu umum, namun yang membedakannya adalah pembelajaran dalam ilmu agama. Mata pelajaran agama di Madrasah Aliyah (MA) diajarkan secara mendalam tanpa mengesampingkan mata pelajaran umum. 
Ilmu menurut pandangan Islam di dalam buku karya Abbudin Nata, dkk merupakan salah satu perantara untuk memantapkan dan menguatkan iman. Iman hanya akan bertambah dan menguat, jika disertai ilmu pengetahuan. Hal ini juga dikuatkan oleh pendapat seorang ilmuan barat Albert Einstein mengatakan bahwa "ilmu tanpa agama buta, dan agama tanpa ilmu adalah lumpuh" (science without religion is blind, and religion without science is lame) (Nata dkk, 2005).

Berdasarkan hasil observasi di beberapa Madrasah Aliyah, ilmu agama dan ilmu umum yang diperoleh peserta didik berjalan sendirisendiri. Keduanya mempunyai wilayah masingmasing, terpisah antara satu dan lainnya, baik dari segi objek formal-material, metode penelitian kriteria kebenaran, dan peran yang dimainkan oleh ilmuwan. Beberapa guru juga belum bisa memberikan pembelajaran dengan memadukan antara ilmu agama dan sains.

Toyyar (2012) secara umum membagi model integrasi keilmuan sains - agama dalam kelompok - kelompok berikut ini, yaitu: Model IFIAS, Model Akademi Sains Islam Malaysia (ASASI), Model Islamic Worldview, Model Struktur Pengetahuan Islam, Model Bucaillisme, Model Integrasi Keilmuan Berbasis Filsafat Klasik, Model Integrasi Keilmuan Berbasis Tasawuf, Model Integrasi Keilmuan Berbasis Fiqh, Model Kelompok Ijmali (Ijmali Group), Model Kelompok Aligargh (Aligargh Group), dan Model Kesatuan Berdasar Konsep Dasar.

Fakhry memberi definisi mengenai konsep Islamisasi terhadap ilmu pengetahuan. Islamisasi berarti upaya memberikan makna keagamaan seperti pada sains, sembari menyadari bahwa sains dapat dikembangkan dalam konteks keagamaan maupun non keagamaan (Fakhry, 2010).

Maksudin (2013) menyatakan bahwa untuk mengintegrasikan pendidikan Sains dan akhlak dalam pembelajaran secara filosofis harus diberi muatan nilai - nilai fundamental, pembekalan ayat
- ayat Al-Qur'an misalnya, dalam kaitannya dengan bidang studi (mata pelajaran) yang bersifat profetik, universal dan humanistik. Hal ini merupakan proses penyadaran bahwa ilmu apapun tidak berdiri sendiri (self-sufficient), dapat dicontohkan di dalam Islam memberi perhatian kepada manusia untuk memperhatikan berbagai fenomena alam dan memikirkannya atau merenungkan keindahan berbagai ciptaan Allah SWT, seperti langit, bumi, jiwa dan semua makhluk yang ada di jagat raya.

Fenomena tersebut menjadi penyebab perlu adanya pengintegrasian antar kedua ilmu yakni agama dan sains agar ciri khas peserta didik di MA dibandingkan peserta didik di SMA dapat terlihat. Integrasi Islam dan sains dapat memunculkan beberapa karakter dari peserta didik, seperti keimanan, kejujuran, kedisiplinan, dan sebagainya. Akan tetapi pada perjalanannya masih jarang adanya buku pelajaran kimia maupun LKS yang mengkaitkan materi pelajaran sains dengan Islam. Selain itu, guru kimia yang kurang mempunyai wawasan keislaman menjadikan pembelajaran kimia yang berbasis Islam-sains tidak mudah untuk diterapkan.

Berdasarkan studi pendahuluan melalui wawancara dengan Ahsanul Wildan, S.Pd sebagai guru pengampu mata pelajaran kimia di MA Salafiyah Simbangkulon, diperoleh informasi bahwa pembelajaran kimia di kelas X selama ini menggunakan LKS. Ketika proses pembelajaran terkadang beliau mengkaitkan materi kimia dengan alam sekitar serta dianalogikan pada kehidupan sehari-hari. Namun, guru belum bisa mengintegrasikan pembelajaran kimia dengan $\mathrm{Al}$ Qur'an. Untuk itu, pengadaan bahan ajar kimia berbasis integrasi Islam-sains dianggap penting guna menunjang kegiatan di kelas.

Pada dasarnya sudah ada penelitian sebelumnya tentang modul pembelajaran yang berbasis integrasi Islam-sains oleh Ririn Maulida (2013), Jurusan Pendidikan Kimia Fakultas Sains dan Teknologi Universitas Islam Negeri Sunan 
Kalijaga Yogyakarta. Namun penelitian ini difokuskan untuk peserta didik berkebutuhan khusus yakni peserta didik difabel netra, sehinga modul yang dikembangkan bertuliskan huruf braille (Maulida, 2013).

Selain itu, penelitian tersebut hanya divalidasi oleh tim ahli dan tidak diuji cobakan kepada peserta didik sehingga tidak dapat diketahui apakah modul tersebut dapat digunakan sebagai referensi guru dalam mengajar maupun penunjang peserta didik dalam belajar mandiri. Hal ini menjadikan tujuan akhir dari pengintegrasian materi sains dengan ayat $\mathrm{Al}$ Qur'an tersebut kurang terarah.

Penelitian ini berusaha mengembangkan bahan ajar kimia yang diintegrasikan dengan Islam. Bahan ajar ini diharapkan menjadi referensi bagi guru dalam mendukung program pemerintah tentang pendidikan karakter dan membantu peserta didik dalam memahami materi pelajaran.

Menurut Azra (2002) memberikan pengertian bahwa pendidikan merupakan suatu proses di mana suatu bangsa mempersiapkan generasi mudanya untuk menjalankan kehidupan dan untuk memenuhi tujuan hidup secara efektif dan efisien. Ditegaskan bahwa pendidikan lebih dari sekedar pengajaran. Pendidikan adalah suatu proses di mana suatu bangsa atau negara membina dan mengembangkan kesadaran diri di antara individu-individu. Jadi, pendidikan pada dasarnya merupakan upaya Peningkatan kemampuan sumber daya manusia supaya dapat menjadi manusia yang mandiri serta dapat berkonstribusi terhadap masyarakat dan bangsanya. Proses pendidikan yang profesional dapat membentuk karakter peserta didik. Karakter dapat dimiliki apabila kita memiliki integritas.

\section{Metode Penelitian}

Metode yang digunakan dalam penelitian ini adalah Research and Development (R\&D). Metode ini bertujuan untuk menghasilkan produk tertentu dan menguji keefektifan produk tersebut (Sugiyono, 2009). Model pengembangan yang digunakan untuk mengembangkan bahan ajar kimia berbasis integrasi Islam-sains adalah model ADDIE. Model ini terdiri dari lima fase atau tahap utama, yaitu (A)nalysis, (D)esign, (D)evelopment, (I)mplementation, dan (E)valuation (Suwahono, 2012).

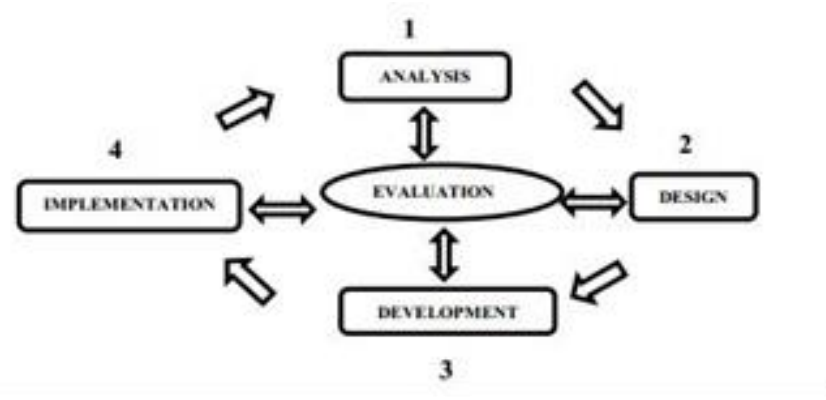

Gambar 1. Model ADDIE

Sampel penelitian ini adalah peserta didik kelas X IPA MA Salafiyah Simbangkulon Pekalongan dengan responden sebanyak 42 peserta didik. Teknik pengumpulan data yang digunakan terdiri atas metode observasi, kuesioner, wawancara, dan tes.

\section{Hasil Penelitian dan Pembahasan}

Hasil angket kebutuhan peserta didik kelas $\mathrm{XP}_{1}$ di MA Salafiyah Simbangkulon Pekalongan dapat dilihat pada Tabel 1. 
Tabel 1. Hasil angket kebutuhan peserta didik

\begin{tabular}{|c|c|c|c|c|c|}
\hline No. & Indikator & Pernyataan & Pilihan & Jumlah & $\%$ \\
\hline \multirow[t]{5}{*}{1} & \multirow[t]{5}{*}{ Kondisi peserta didik } & \multirow{5}{*}{$\begin{array}{l}\text { Usia peserta } \\
\text { didik }\end{array}$} & 14 tahun & 4 & $10 \%$ \\
\hline & & & 15 tahun & 30 & $71 \%$ \\
\hline & & & 16 tahun & 6 & $14 \%$ \\
\hline & & & 17 tahun & 2 & $5 \%$ \\
\hline & & & Lainnya & 0 & $0 \%$ \\
\hline \multirow[t]{15}{*}{2} & \multirow{15}{*}{$\begin{array}{c}\text { Keadaan belajar peserta } \\
\text { didik }\end{array}$} & \multirow{5}{*}{$\begin{array}{c}\text { Waktu } \\
\text { mengulang } \\
\text { pelajaran/ } \\
\text { belajar di rumah }\end{array}$} & Sepulang sekolah & 7 & $17 \%$ \\
\hline & & & Sore hari & 3 & $7 \%$ \\
\hline & & & Malam hari & 19 & $45 \%$ \\
\hline & & & Setelah shubuh & 11 & $26 \%$ \\
\hline & & & Lainnya & 2 & $5 \%$ \\
\hline & & \multirow{5}{*}{$\begin{array}{l}\text { Durasi belajar di } \\
\text { rumah }\end{array}$} & $<1$ jam & 25 & $60 \%$ \\
\hline & & & 1jam & 10 & $24 \%$ \\
\hline & & & 2jam & 2 & $5 \%$ \\
\hline & & & $>2$ jam & 2 & $5 \%$ \\
\hline & & & Lainnya & 3 & $6 \%$ \\
\hline & & \multirow{5}{*}{$\begin{array}{c}\text { Keadaan belajar } \\
\text { terhadap } \\
\text { pemahaman }\end{array}$} & Mendengarkan guru & 9 & $21 \%$ \\
\hline & & & Belajar sendiri dirumah & 13 & $31 \%$ \\
\hline & & & Belajar dibimbel & 7 & $17 \%$ \\
\hline & & & Bertanya pada teman & 11 & $26 \%$ \\
\hline & & & Lainnya & 2 & $5 \%$ \\
\hline \multirow[t]{5}{*}{3} & \multirow[t]{5}{*}{ Materi kimia } & \multirow{5}{*}{$\begin{array}{l}\text { Materi kimia } \\
\text { yang disukai } \\
\text { peserta didik }\end{array}$} & Teori atom\&SPU & 17 & $40.5 \%$ \\
\hline & & & Ikatan Kimia & 5 & $12 \%$ \\
\hline & & & Stoikiometri & 3 & $7 \%$ \\
\hline & & & Larutan elektrolit \& nonelektrolit & 17 & $40,5 \%$ \\
\hline & & & Lainnya & 0 & 0 \\
\hline \multirow[t]{15}{*}{4} & \multirow[t]{15}{*}{ Metode pembelajaran } & \multirow[t]{5}{*}{ Nilai UAS kimia } & $<60$ & 8 & $19 \%$ \\
\hline & & & $<66$ & 20 & $48 \%$ \\
\hline & & & 80 & 7 & $17 \%$ \\
\hline & & & 90 & 4 & $9 \%$ \\
\hline & & & Lainnya & 3 & $7 \%$ \\
\hline & & \multirow{5}{*}{$\begin{array}{c}\text { Metode yang } \\
\text { sering diterapkan }\end{array}$} & Ceramah & 27 & $64 \%$ \\
\hline & & & Diskusi & 5 & $12 \%$ \\
\hline & & & Praktikum & 0 & 0 \\
\hline & & & Permainan & 0 & 0 \\
\hline & & & Lainnya & 10 & $24 \%$ \\
\hline & & \multirow{5}{*}{$\begin{array}{l}\text { Metode yang } \\
\text { diinginkan } \\
\text { peserta didik }\end{array}$} & Ceramah & 17 & $40 \%$ \\
\hline & & & Diskusi & 10 & $24 \%$ \\
\hline & & & Praktikum & 7 & $17 \%$ \\
\hline & & & Permainan & 6 & $14 \%$ \\
\hline & & & Lainnya & 2 & $5 \%$ \\
\hline \multirow[t]{10}{*}{5} & \multirow[t]{10}{*}{ Bahan ajar } & \multirow{5}{*}{$\begin{array}{c}\text { Bahan ajar kimia } \\
\text { yang digunakan }\end{array}$} & LKS & 13 & $30 \%$ \\
\hline & & & Buku Paket & 7 & $17 \%$ \\
\hline & & & Modul & 20 & $48 \%$ \\
\hline & & & Handout & 0 & 0 \\
\hline & & & Lainnya & 2 & $5 \%$ \\
\hline & & \multirow{5}{*}{$\begin{array}{c}\text { Bahan ajar cetak } \\
\text { yang diinginkan } \\
\text { peserta didik }\end{array}$} & Ada ilustrasi gambar & 10 & $24 \%$ \\
\hline & & & Ada kalimat motivasi & 3 & $7 \%$ \\
\hline & & & Dikaitkan dengan Al-Qur'an \& Hadis & 17 & $40 \%$ \\
\hline & & & Dikaitkan dengan kehidupan sehari-hari & 12 & $29 \%$ \\
\hline & & & Lainnya & 0 & 0 \\
\hline
\end{tabular}


Berdasarkan data yang diperoleh dalam Tabel 1 di atas, dapat diketahui bahwa sebagian besar peserta didik berusia 15 tahun. Hal ini mengungkapkan bahwa mayoritas kondisi psikologis maupun keadaan fisik peserta tidak jauh berbeda karena 71\% dari mereka berusia 15 tahun. Selain itu, dapat diketahui pula bahwa sebanyak $45 \%$ peserta didik mengulang pelajaran atau belajar di rumah pada malam hari. Sedangkan durasi belajar peserta didik 60\% dari mereka belajar selama $<1$ jam. Adapun pemahaman peserta didik terhadap materi pelajaran beragam, tetapi sebagian besar dari peserta didik lebih memahami pelajaran ketika belajar sendiri di rumah.

Materi kimia yang paling banyak disukai oleh peserta didik adalah materi teori atom dan SPU serta materi larutan elektrolit dan non elektrolit. Hal ini mengungkapkan bahwa sebagian besar peserta didik menyukai materi kimia yang berupa teori maupun konsep daripada materi yang berupa hitungan. Nilai UAS semester gasal $67 \%$ peserta didik adalah $<66$. Hal ini dapat disimpulkan bahwa lebih dari setengah peserta didik mendapatkan nilai UAS di bawah KKM.

Berdasarkan hasil analisis angket kebutuhan peserta didik, sebanyak $40 \%$ peserta didik mengatakan bahwa pembelajaran kimia selama ini lebih sering menggunakan metode ceramah. Sebagian besar dari peserta didik juga menginginkan metode ceramah tetap diterapkan dalam pembelajaran. Sebanyak $48 \%$ peserta didik menyatakan bahwa bahan ajar yang selama ini digunakan dalam pembelajaran adalah modul. Sedangkan bahan ajar cetak yang diinginkan sebagian besar peserta didik adalah bahan ajar yang dikaitkan dengan Al-Qur'an dan Hadits.

Berdasarkan analisis kebutuhan peserta didik terhadap bahan ajar kimia dapat ditarik kesimpulan sementara bahwa adanya bahan ajar kimia berbasis integrasi Islam sains merupakan bahan ajar yang diperlukan peserta didik kelas X MA Salafiyah Simbangkulon Pekalongan.

Tahap perancangan bahan ajar kimia berbasis integrasi Islam-Sains dilaksanakan selama kurang lebih satu bulan dari tanggal 10 Februari 2014 sampai 12 Maret 2014. Tahap awal perancangan tersebut diawali dengan kegiatan menentukan tujuan pembelajaran peserta didik dalam ranah kognitif, ranah psikomotorik, dan ranah afektif dan tujuan akhirnya adalah efektif dalam mendukung pembelajaran kimia. Tahap kedua menentukan strategi pembelajaran yang tepat yaitu dengan menggunakan metode diskusi untuk mencapai tujuan tersebut. Dalam langkah diskusi ini peserta didik bisa berpendapat dengan bebas mengenai minyak bumi.

Tahap ketiga yaitu membuat rancangan bahan ajar, bahan ajar yang dikembangkan adalah bahan ajar kimia berbasis integrasi Islam-Sains meliputi cover bahan ajar, kata pengantar, daftar isi, dan isi materi pelajaran kimia materi minyak bumi yang di dalamnya terdapat konsep minyak bumi menurut sains dan menurut islam yang disertai dengan ayat Qur'an maupun Hadits, gambar-gambar yang disesuaikan dengan materi yang dapat dijumpai dalam kehidupan sehari-hari, kata-kata motivasi yang dapat memotivasi peserta didik dalam belajar, kolom refleksi di setiap akhir materi agar peserta didik mampu memaknai materi yang sudah dipelajari dengan bahasanya sendiri, profil ilmuwan muslim, soal penguasaan di akhir sub bab guna mengevaluasi pemahaman peserta didik terhadap materi yang baru dipelajari, uji kompetensi di akhir bahan ajar, glosarium, daftar pustaka. Bahan ajar didesain sedemikian rupa sehingga peserta didik tertarik untuk belajar kimia. Desain bahan ajar dapat dilihat sebagai berikut. 


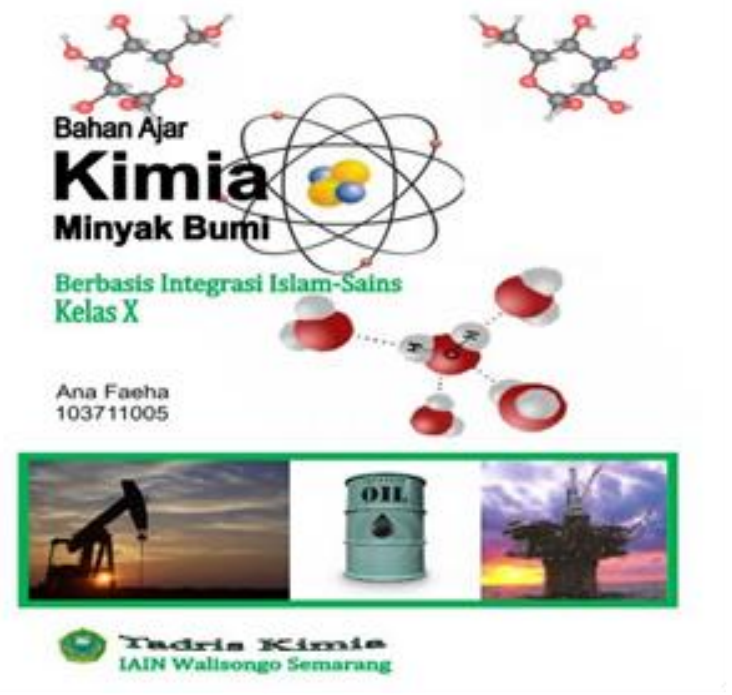

Setelah tahap perancangan desain bahan ajar selesai dilakukan, maka dilanjutkan dengan tahap validasi oleh pakar yang ahli dalam hal media pembelajaran kimia dan konten materi kimia. Tim validator terdiri atas dua dosen ahli dan satu guru kimia. Validasi dilakukan dengan menggunakan instrumen KTSP dan instrumen kurikulum 2013 (sebagai rekomendasi) sehingga bahan ajar yang dikembangkan dapat digunakan secara berkelanjutan sesuai dengan kurikulum yang berlaku.

Berdasarkan hasil validasi, dapat diketahui bahwa bahan ajar kimia berbasis integrasi IslamSains yang dikembangkan melalui model desain ADDIE layak untuk digunakan sebagai media pembelajaran pada materi pokok minyak bumi kelas X. Hal ini dibuktikan dengan nilai rata-rata validasi yang diperoleh dari dosen ahli media dan materi sebesar 3.14 dan 3.97 (pada instrumen validasi kurikulum 2013) dan nilai rata-rata 4.23 (pada instrumen validasi KTSP). Adapun hasil validasi yang dilakukan oleh guru diperoleh nilai rata-rata 4.14 (pada instrumen validasi kurikulum 2013) dan nilai rata-rata 4.06 serta 4.86 (pada instrumen validasi KTSP).
Tahap selanjutnya setelah diperoleh kriteria kelayakan bahan ajar yaitu tahap pengembangan (development). Pada tahap ini dilakukan dengan melakukan uji coba pada 9 peserta didik yang dipilih secara acak berdasarkan kemampuan penguasaan materi pembelajaran dari kelompok kelas atas, menengah, dan kelompok kelas bawah. Uji coba ini dimaksudkan untuk mengetahui kelayakan dan efektifitas penggunaan bahan ajar pada kelas kecil. Hasil uji coba kelas kecil pada aspek kognitif diperoleh nilai rata-rata sebesar 77.66 (kriteria efektif), aspek afektif sebesar 76.86, dan aspek psikomotorik sebesar 75.6 dengan persentase tingkat ketuntasan 100\%. Adapun tingkat keterbacaan bahan ajar yang diperoleh berdasarkan tes isian rumpang adalah sebesar 69.4\% (kategori independen). Berdasarkan hasil yang diperoleh, maka bahan ajar yang dikembangkan ini layak untuk diterapkan pada pembelajaran kelas besar.

Implementasi bahan ajar kimia berbasis integrasi Islam-Sains di kelas besar dilakukan terhadap 35 peserta didik di kelas $\mathrm{XP}_{1}$. Nilai rata-rata yang diperoleh pada tes evaluasi kognitif sebesar 76.82 dengan persentase tingkat ketuntasan 100\% (kriteria efektif). Adapun nilai rata-rata yang diperoleh pada aspek afektif sebesar 71.2 dengan tingkat ketuntasan 97.1\%. pada aspek psikomotorik diperoleh nilai rata-rata sebesar 75.6 dengan tingkat ketuntasan 100\%. Hasil tes isian rumpang menunjukkan bahwa tingkat keterbacaan bahan ajar pada kelas besar termasuk kategori independen dengan persentase sebesar $66.6 \%$. 


\section{Kesimpulan}

Secara keseluruhan, berdasarkan hasil penelitian yang diperoleh, bahan ajar kimia berbasis integrasi Islam-Sains yang berhasil dikembangkan termasuk layak digunakan dalam mendukung pembelajaran kimia. Namun, bahan ajar ini perlu dikembangkan pada skala yang lebih luas yaitu pada kelas lain, oleh guru lain di sekolah yang sama ataupun di sekolah berbeda.

\section{Referensi}

Azra. (2002). Paradigma Baru Pendidikan Nasional. Jakarta : Rekonstruksi dan Demokratisasi

Baiquni, A. (1995). Al-Quran, Ilmu Pengetahuan dan Teknologi. Yogyakarta : dana Bhakti Wakaf

Chang, R. (2004). Kimia Dasar Konsep-konsep Inti Jilid 1. Jakarta: Erlangga.
Fakhry, J. (2010). Sains dan Teknologi dalam AlQuran dan Implikasinya dalam Pembelajaran. Ta'dib, 15(1)

Maksudin. (2013). Pendidikan Karakter Non Dikotomik. FTK UIN Sunan Kalijaga Cetakan ke 1. Yogyakarta

Maulida, R. (2013). Energi dan Perubahannya Pengembangan Modul Pembelajaran Sains Berbasis Integrasi Islam-Sains untuk Peserta Didik Difabel Netra MI/SD Kelas 5 Semester 2 Materi Pokok. Skripsi. Yogyakarta: UIN Sunan Kalijaga.

Nata, A., dkk. (2005). Integrasi Ilmu Agama dan Ilmu Umum. Jakarta: PT Raja Grafindo Persada. Sugiyono. (2009). Metode Penelitian Kuantitatif, Kualitatif dan R\&D. Bandung: Alfabeta.

Suwahono. (2012). Metodologi Penelitian Pendidikan Kimia. t.t.p: t.p.

Thoyyar. (2012). Model-Model Integrasi Ilmu dan Upaya Membangun Landasan Keilmuan Islam 